Article

\title{
Synthesis of Vitamin B3 through a Heterogeneous Photocatalytic Approach Using Metal-Free Carbon Nitride-Based Catalysts
}

\author{
Raquel A. Fernandes ${ }^{1,2,+}$, Maria J. Sampaio ${ }^{1,2,+} \mathbb{D}$, Joaquim L. Faria ${ }^{1,2} \mathbb{D}$ and Cláudia G. Silva ${ }^{1,2, *} \mathbb{D}$ \\ 1 ALiCE-Associate Laboratory in Chemical Engineering, Faculty of Engineering, University of Porto, \\ Rua Dr. Roberto Frias, 4200-465 Porto, Portugal; raquel.fernandes@fe.up.pt (R.A.F.); \\ mjsampaio@fe.up.pt (M.J.S.); jlfaria@fe.up.pt (J.L.F.) \\ 2 LSRE-LCM - Laboratory of Separation and Reaction Engineering-Laboratory of Catalysis and Materials, \\ Faculty of Engineering, University of Porto, Rua Dr. Roberto s/n, 4200-465 Porto, Portugal \\ * Correspondence: cgsilva@fe.up.pt \\ + These authors contributed equally to this work.
}

Citation: Fernandes, R.A.; Sampaio, M.J.; Faria, J.L.; Silva, C.G. Synthesis of Vitamin B3 through a Heterogeneous Photocatalytic Approach Using Metal-Free Carbon Nitride-Based Catalysts. Molecules 2022, 27, 1295. https://doi.org/ $10.3390 /$ molecules 27041295 Academic Editor: Mathias O. Senge

Received: 14 January 2022 Accepted: 8 February 2022 Published: 15 February 2022

Publisher's Note: MDPI stays neutral with regard to jurisdictional claims in published maps and institutional affiliations.

Copyright: (C) 2022 by the authors. Licensee MDPI, Basel, Switzerland. This article is an open access article distributed under the terms and conditions of the Creative Commons Attribution (CC BY) license (https:// creativecommons.org/licenses/by/ $4.0 /)$.

\begin{abstract}
Vitamin B3 (nicotinic acid, VB3) was synthesized through the photocatalytic oxidation of 3-pyridinemethanol (3PM) under visible-light-emitting diode (LED) irradiation using metal-free graphitic carbon nitride $(\mathrm{GCN})$ - based materials. A bulk (GCN) material was prepared by a simple thermal treatment using dicyandiamide as the precursor. A post-thermal treatment under static air and nitrogen flow was employed to obtain the GCN-T and GCN-T-N materials, respectively. The conditions adopted during the post-treatment revealed differences in the resulting materials' morphological, electronic, and optical properties. The post-treated photocatalysts revealed an enhanced efficiency in the oxidation of 3PM into VB3, with the GCN-T-N photocatalyst being the best-performing material. The defective surface, reduced crystallinity, and superior photoabsorption of GCN-T-N account for this material's improved performance in the production of VB3. Nevertheless, the presence of nitrogen vacancies in the carbon nitride structure and, consequently, the creation of mid-gap states also accounts to its highly oxidative ability. The immobilization of GCN-T-N in sodium alginate hydrogel was revealed as a promising strategy to produce VB3, avoiding the need for the photocatalyst separation step. Concerning the mechanism of synthesis of VB3 through the photocatalytic oxidation of 3PM, it was possible to identify the presence of 3-pyridinecarboxaldehyde $(3 \mathrm{PC})$ as the intermediary product.
\end{abstract}

Keywords: Vitamin B3; carbon nitride; photocatalysis; organic synthesis

\section{Introduction}

Vitamin B3 (or nicotinic acid) is a water-soluble vitamin that acts as a building block in the synthesis of nicotinamide-adenine-dinucleotide (NAD), playing an essential role in the redox reactions occurring in living cells [1]. The primary application of vitamin B3 is in medicine - namely, in treating pellagra disease and alcoholism [2] - leading to an annual production of more than 22,000 tons worldwide [1]. Currently, most vitamin B3 is chemically produced by the ammoxidation and oxidation of pyridines under high pressure and alkali conditions, with a massive energetic demand and the generation of hazardous effluents $[1,3]$. Heterogeneous photocatalysis has been explored as a valuable and more sustainable alternative to the conventional synthesis processes, using 3-pyridinemethanol as a starting molecule. Spasiano et al. [3] used titanium dioxide $\left(\mathrm{TiO}_{2}\right)$ photocatalyst to convert 3-pyridinemethanol into vitamin B3 without oxygen under a high-pressure UV lamp, achieving a $30 \%$ conversion and $87 \%$ selectivity after $0.75 \mathrm{~h}$ of irradiation. Using $\mathrm{TiO}_{2}$ nanotubes, Yurdakal et al. [4] reached a 15\% conversion and 35\% selectivity in the synthesis of vitamin B3 under an oxygenated atmosphere and a fluorescent lamp light 
source. The same research group registered an increase in the selectivity (45\%) by doping home-prepared $\mathrm{TiO}_{2}$ with platinum in alkaline conditions ( $\mathrm{pH} 12$ ) after $3 \mathrm{~h}$ of irradiation [5]. Alfè et al. [6] reported the use of a heterojunction strategy, combining $\mathrm{TiO}_{2}$ and graphene to increase the conversion of the alcohol and achieving a maximum value of $65 \%$ after $5 \mathrm{~h}$ of irradiation by a mercury lamp under a continuous nitrogen flow. More recently, Sobahi et al. [7] explored the performance of a heterojunction of metal-doped $\mathrm{TiO}_{2}\left(\mathrm{Ag} @ \mathrm{TiO}_{2}\right)$ and carbon nitride under oxygenated conditions. After $9 \mathrm{~h}$ of irradiation with a halogen lamp, researchers reached a $100 \%$ alcohol conversion and $100 \%$ selectivity for the synthesis of vitamin B3.

$\mathrm{TiO}_{2}$-based materials have a significant prevalence concerning the photocatalytic synthesis of vitamin B3 owing to their resulting conversion and selectivity. The use of added metal phases creates several concerns: the possibility of leaching and the lack of sustainability arising from the decreasing availability of some used metals. Concerning artificial processes of photocatalyst activation, the traditional use of low-efficiency irradiation sources, such as halogen and fluorescent lamps, severely threatens the energetic sustainability of conventional light-activated processes. Therefore, the replacement of light sources by light-emitting diodes (LEDs) may account for the environmental sustainability of the process by increasing the energy efficiency and, consequently, increasing the effectiveness of irradiation. The use of carbon-based metal-free semiconductors as photocatalysts circumvents the environmental issues associated with the use of metal-based materials. Among several carbon materials, graphite-like carbon nitride (here labeled as GCN) has gained much attention in photocatalytic systems due to its absorption in the visible region of spectra up to c.a. $460 \mathrm{~nm}$, easy synthesis through the thermal condensation of Earth-abundant and low-cost precursors, nontoxicity, and chemical stability [8,9]. However, its low surface area, high recombination rate between electrons $\left(\mathrm{e}^{-}\right)$and photogenerated holes $\left(\mathrm{h}^{+}\right)$, and limited absorption of visible radiation negatively affect its photocatalytic performance [8-12]. Among all the methods adopted to overcome the drawbacks of GCN, thermal exfoliation has proven to be highly efficient in tuning its optical, morphological, and electronic properties [13-15]. The heating process breaks the hydrogen bonds responsible for the aggregation between the layers of GCN, leading to the splitting of graphite-like sheets [14,16-18] and introducing defects on the surface of the catalyst $[13,19,20]$, generally resulting in an enhancement in the photocatalytic activity of the resulting materials.

For the first time, the present work reports the use of powder metal-free catalysts to produce vitamin B3 through the oxidation of 3-pyridinemethanol under visible-LED irradiation. Bulk GCN was thermally post-treated under air (resulting in the designated GCN-T) and then under nitrogen atmosphere (GCN-T-N). The thermally modified catalysts were thoroughly characterized to assess the effect of the thermal post-treatment conditions on their properties. Concerning the advantages of immobilized catalysts in an industrial context, an additional study was also performed using a GCN-T-N catalyst immobilized on a sodium alginate substrate.

\section{Results and Discussion}

\subsection{Characterization of the GCN-Based Photocatalysts}

Bulk GCN and thermally post-treated materials under air (GCN-T) and nitrogen (GCN-T-N) atmosphere were morphologically characterized through scanning electron microscopy (SEM). Representative micrographs are presented in Figure 1.

It is reported that bulk GCN (Figure 1a) presents a highly stacked structure, resulting in a low $S_{\mathrm{BET}}$, which is also observed in this work $\left(7 \mathrm{~m}^{2} \mathrm{~g}^{-1}\right.$, Table 1$)$. In GCN-T-N (Figure $\left.1 \mathrm{~b}\right)$, a defective porous surface may be observed, reflected in an increase in its $S_{\text {BET }}\left(22 \mathrm{~m}^{2} \mathrm{~g}^{-1}\right.$, Table 1). The thickness of the graphite-like layers of GCN-T (Figure 1c) decreases due to the breaking of van der Waals forces and hydrogen bonds during the thermal post-treatment at $500{ }^{\circ} \mathrm{C}$, resulting in a significant increase in the $S_{\mathrm{BET}}\left(60 \mathrm{~m}^{2} \mathrm{~g}^{-1}\right.$; Table 1) $[16,18]$. This fact is in line with the pore diameter distribution of GCN-based materials (Figure 1d). The pore diameter of GCN and GCN-T materials seems to be related to the interstices/distance 
between the carbon nitride layers once these materials did not exhibit pores on their surface. Bulk GCN has an almost negligible pore diameter (Figure 1d), which is in agreement with its compact stacked lamellar structure (Figure 1a).
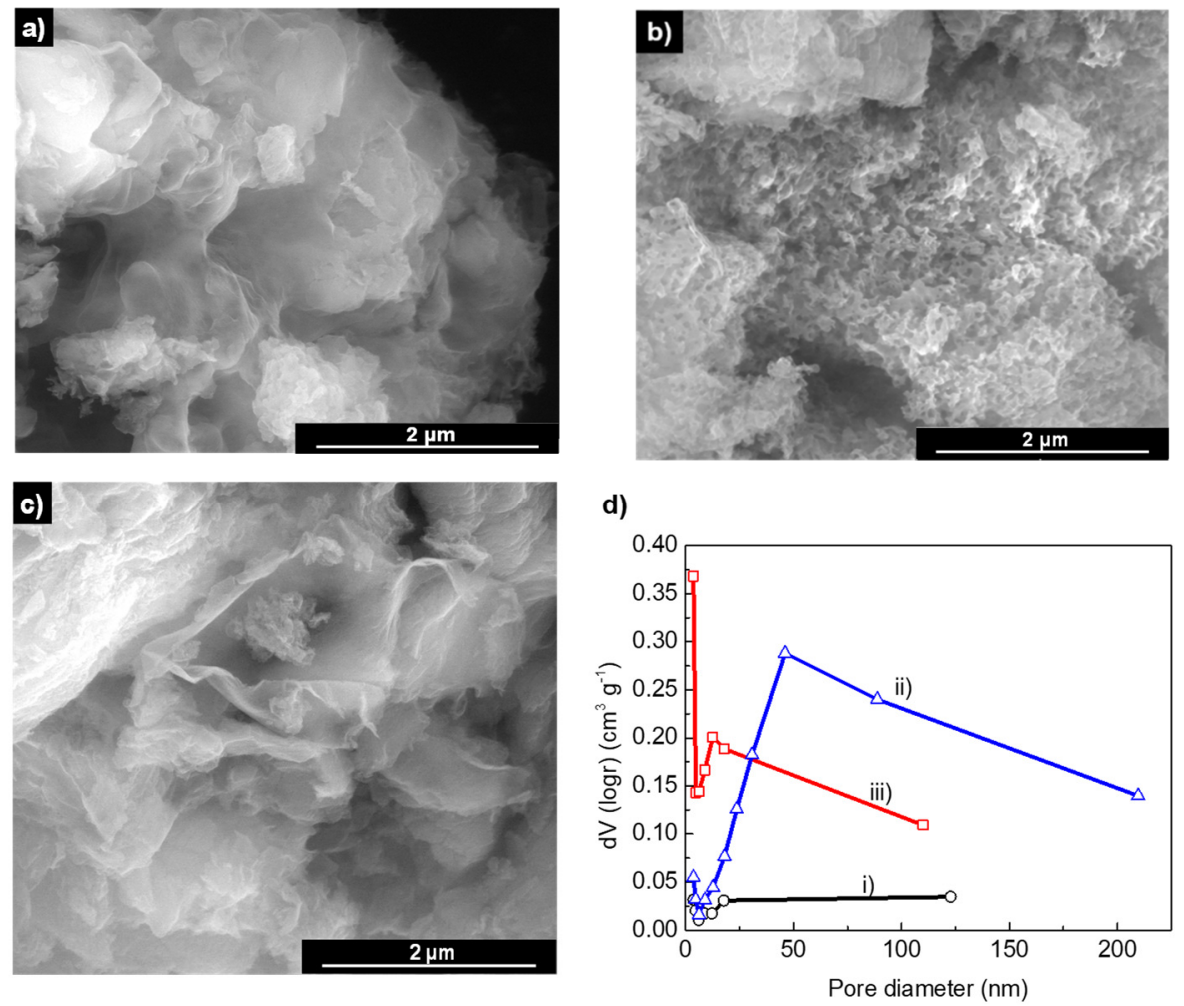

Figure 1. SEM micrographs of (a) GCN, (b) GCN-T-N, and (c) GCN-T. (d) Barrett-Joyner-Halenda pore volume distribution derived from the $\mathrm{N}_{2}$ adsorption isotherms of (i) GCN, (ii) GCN-T-N, and (iii) GCN-T at $-196^{\circ} \mathrm{C}$.

Table 1. The atomic ratio between carbon and nitrogen, specific surface area $\left(S_{\mathrm{BET}}\right), \mathrm{XRD}$ peak $(002)$ width at half height (FWHM), and crystallite size $(d)$ of the synthesized catalysts.

\begin{tabular}{ccccc}
\hline Catalyst & $\boldsymbol{S}_{\text {BET }}\left(\mathbf{m}^{\mathbf{2}} \mathbf{g}^{-\mathbf{1}}\right)$ & C/N Ratio & FWHM $\left(^{\circ}\right)$ & $\boldsymbol{d}(\mathbf{n m})$ \\
\hline GCN & 7 & 0.56 & 2.09 & 4.2 \\
GCN-T & 60 & 0.56 & 2.23 & 3.9 \\
GCN-T-N & 22 & 0.58 & 2.54 & 3.8 \\
\hline
\end{tabular}

GCN-T-N presents a broad distribution of pore diameter (from $3.6 \mathrm{~nm}$ to $210 \mathrm{~nm}$ ) and exhibits a high number of larger pores (Figure 1d). In GCN-T, the pore diameter distribution varies from $3.6 \mathrm{~nm}$ to $110 \mathrm{~nm}$ (Figure $1 \mathrm{~d}$ ).

Defects may occur on the surface of carbon nitride materials due to the presence of nitrogen vacancies in heptazine rings $[13,19]$. The determination of the $\mathrm{C} / \mathrm{N}$ ratio obtained from the atomic composition through elemental analysis revealed an increase from 0.56 (GCN and GCN-T, Table 1) to 0.58 (GCN-T-N, Table 1), which may indicate the loss of nitrogen atoms in the aromatic units. XPS analyses revealed a decrease in the atomic content of nitrogen at the catalyst surface for the GCN-T-N compared with bulk GCN (Supplementary Material, Figure S1 and Table S1). This is reflected in the higher C/N ratio observed by XPS for GCN-T-N when compared with the bulk GCN (0.87 and 0.83, respectively), which are in accordance with the results obtained by elemental analysis.

The XRD analysis (Figure 2) confirmed that all GCN-based catalysts exhibit the prominent peaks of carbon nitride materials. The diffraction peak at $27^{\circ}$ corresponds to the (002) plane and was ascribed to the distance between the graphitic layers [21,22]. A minor peak 
was also identified at $13^{\circ}$, attributed to the (100) plane and correlated to the intralayer spacing [21,22]. In the case of GCN-T-N, a sharp decrease was observed in the intensity of both XRD peaks (Figure 2), suggesting a less crystalline structure with no atomic order when compared to bulk GCN and GCN-T, possibly due to its holey surface that creates a highly distorted structure [23]. Additionally, this material exhibited a higher value for the full-width at half-height (FWHM, Table 1) of the (002) peak with relation to bulk GCN and GCN-T, which confirms the decrease in the crystallinity of the material, resulting from the thermal treatment under a nitrogen atmosphere. The high-intensity (002) peak in the XRD spectra of GCN-T follows the previous findings of splitting the carbon nitride layers upon thermal treatment under air. The average crystallite size (d, Table 1) was calculated through the Debye-Scherrer equation $[17,24]$ (see Supporting Data) and followed the order GCN > GCN-T > GCN-T-N, which corroborated the loss of crystallinity in the case of GCN-T-N.

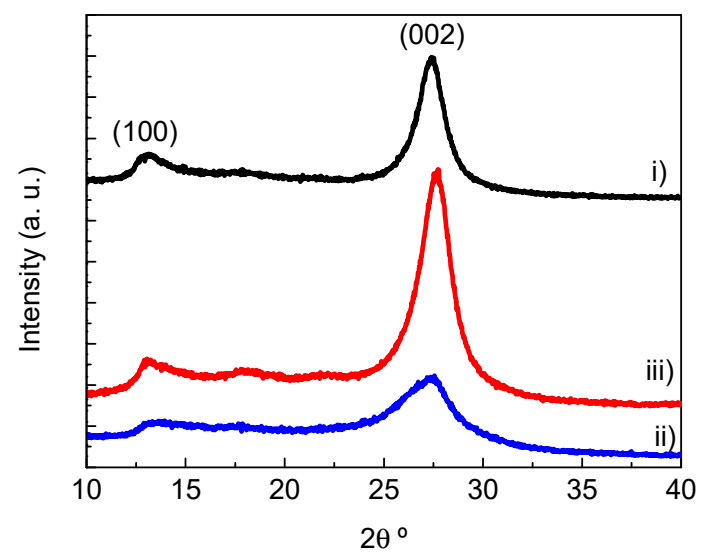

Figure 2. XRD pattern of (i) GCN, (ii) GCN-T-N, and (iii) GCN-T catalysts.

The optical and electronic properties of GCN-based catalysts were evaluated through DR UV-vis and PL spectroscopies (Figure 3).

a)

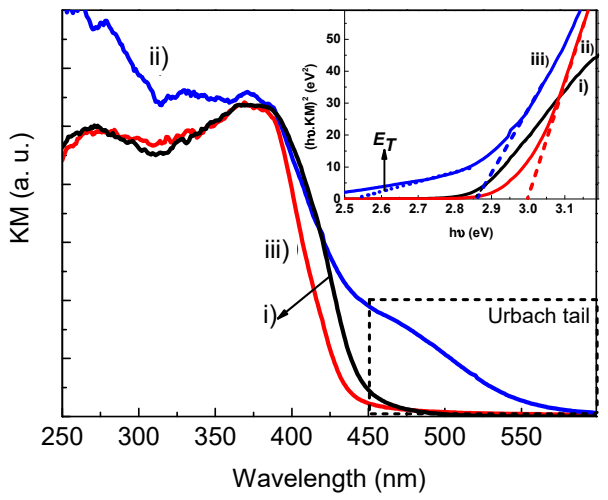

b)

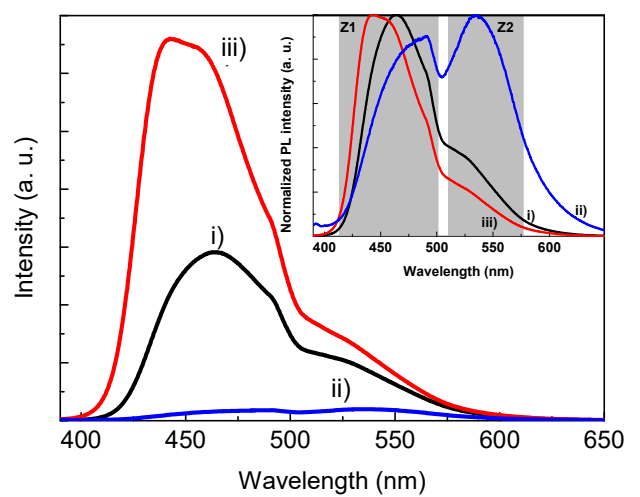

Figure 3. (a) DR UV-vis spectra (inset is shown the respective Tauc plots) and (b) PL spectra (inset is shown the normalized PL spectra) of (i) GCN, (ii) GCN-T-N, and (iii) GCN-T. Highlighted zones Z1 and $\mathrm{Z} 2$ indicate the two PL emission bands.

As previously reported $[11,12,16,18]$, bulk GCN and GCN-T present similar UV-vis spectra, with an intense absorption band up to c.a. $450 \mathrm{~nm}$ (Figure 3a) and a bandgap energy (Eg) of $2.86 \mathrm{eV}$ and $3.00 \mathrm{eV}$ (inset Figure 3a), respectively.

Regarding GCN-T-N, the extension in the absorption up to $550 \mathrm{~nm}$ (Urbach tail, Figure 3a) is directly related to the change verified in the color of the catalyst from yellow (GCN) to orange (GCN-T-N). 
According to the literature, the presence of an Urbach tail in the DR UV-vis spectra is usually ascribed to $n-\pi^{*}$ electronic transitions promoted by the existence of mid-gap states located within the bandgap $[11,25,26]$. These intermediary states of energy may favor the separation of the photogenerated electrons $\left(\mathrm{e}^{-}\right)$and holes $\left(\mathrm{h}^{+}\right)$, preventing their recombination and allowing the catalyst to absorb photons with energies below its bandgap $[11,25,26]$. Additionally, Tauc plot analysis (inset Figure 3a) corroborates the existence of additional electronic transitions in GCN-T-N, since it is possible to observe the energy of transition $\left(\mathrm{E}_{\mathrm{T}}\right.$, inset Figure $\left.3 \mathrm{a}\right)$ associated with the electronic potential of the mid-gap state $(2.54 \mathrm{eV})$.

In terms of PL, GCN-T displays an intense emission compared to the parent GCN (Figure 3b), which may be attributed to the loss of amino groups during the thermal treatment, promoting defects on the GCN matrix acting as active sites for $\mathrm{e}^{-} / \mathrm{h}^{+}$recombination [11,26-28]. On the other hand, GCN-T-N emission is much reduced compared to bulk GCN (Figure 3b) due to the modified arrangement of $\mathrm{C}$ and $\mathrm{N}$ atoms in the carbon nitride matrix [23]. A blue shift in the maximum of PL intensity of GCN-T can be observed when compared to bulk GCN (from $463 \mathrm{~nm}$ to $444 \mathrm{~nm}$, inset Figure 3b, highlighted zone $\mathrm{Z1}$ ), which can be attributed to the decrease in the thickness of the carbon nitride layers in the case of GCN-T [27]. Contrariwise, GCN-T-N presents a PL red-shift from $463 \mathrm{~nm}$ to 489 nm (inset Figure 3b, highlighted zone Z1) due to the extension of the carbon nitride network when it is subjected to higher temperatures, with the $\pi$ states hybridizing into a broad state [10]. This band of PL emission is usually ascribed to the recombination rate of $\mathrm{e}^{-}$and $\mathrm{h}^{+}$in the $\pi$-conjugated system of graphite-like structures $[11,12,26]$. A second PL band related to the $n-\pi^{*}$ electronic transitions in the lone pairs of electrons of $\mathrm{N}$ atoms is also observed at $528 \mathrm{~nm}$ (inset Figure 3b, zone Z2) [11,12,26]. According to the literature, distorted structures, such as GCN-T-N, have a positive contribution to the occurrence of this type of electronic transition $[11,12,26]$. Therefore, the electronic excitation in GCN-T-N may be more effective due to the contributions of the two types of transitions.

\subsection{Photocatalytic Results}

The photocatalytic performance of GCN, GCN-T, and GCN-T-N materials was studied in the selective oxidation of 3-pyridinemethanol (3PM) into Vitamin B3 (VB3) under visibleLED irradiation $\left(\lambda_{\max }=412 \mathrm{~nm}\right)$.

The starting alcohol revealed a high photochemical stability under the irradiation conditions adopted, with no 3PM conversion being observed after $7 \mathrm{~h}$ of irradiation in the absence of catalyst (data not shown), which was already expected due to the lack of light absorption of this molecule in the wavelength of irradiation of the visible-LED system (Supplementary Material, Figure S2).

As displayed in Figure 4a, the 3-pyridinemethanol (3PM) achieved complete conversion (oxidation) after $3 \mathrm{~h}$ using the GCN-T-N photocatalyst. In addition, using the same photocatalyst, the formation of the intermediate 3-pyridinecarboxaldehyde (3PC) with the concomitant production of Vitamin B3 (nicotinic acid, VB3) can be observed in Figure 4b,c, respectively. After $1 \mathrm{~h}$ of reaction, the maximum concentration of the intermediate $3 \mathrm{PC}$ occurred, then was converted to VB3 (Figure 4c).

This behavior was also observed for bulk GCN and GCN-T photocatalysts. However, the conversion of 3PM showed slower kinetics for both photocatalysts, requiring $3 \mathrm{~h}$ for the complete conversion of the starting molecule (3PM). 
a)

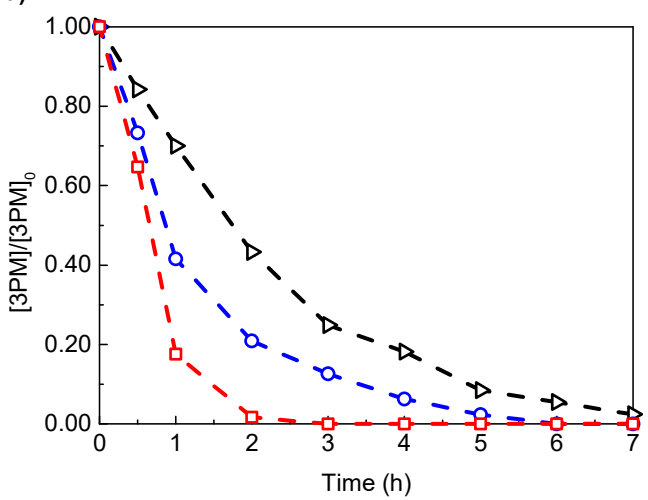

c)
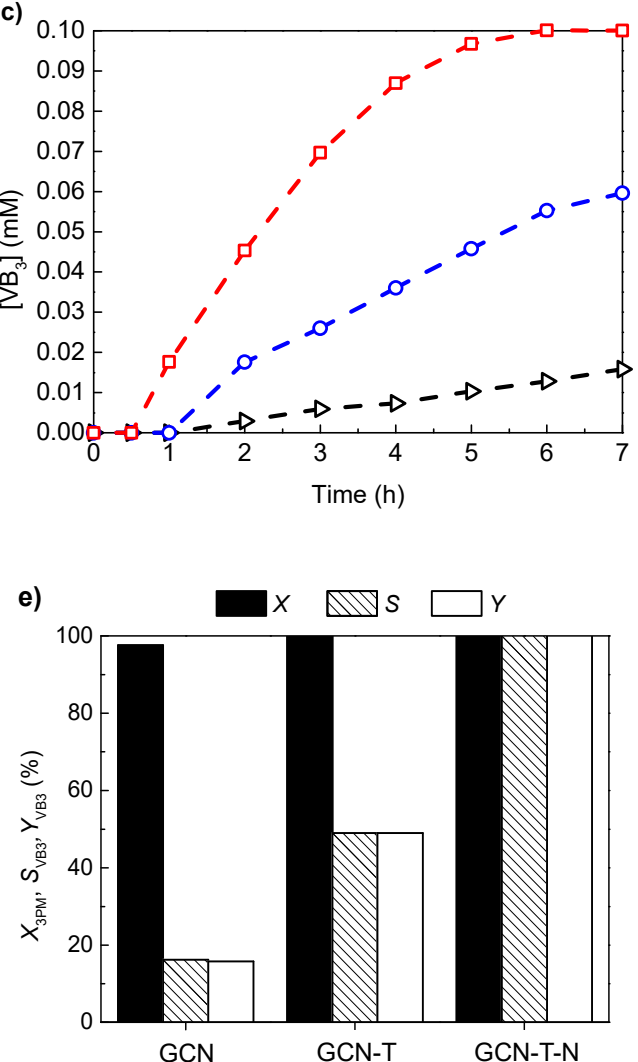

b)
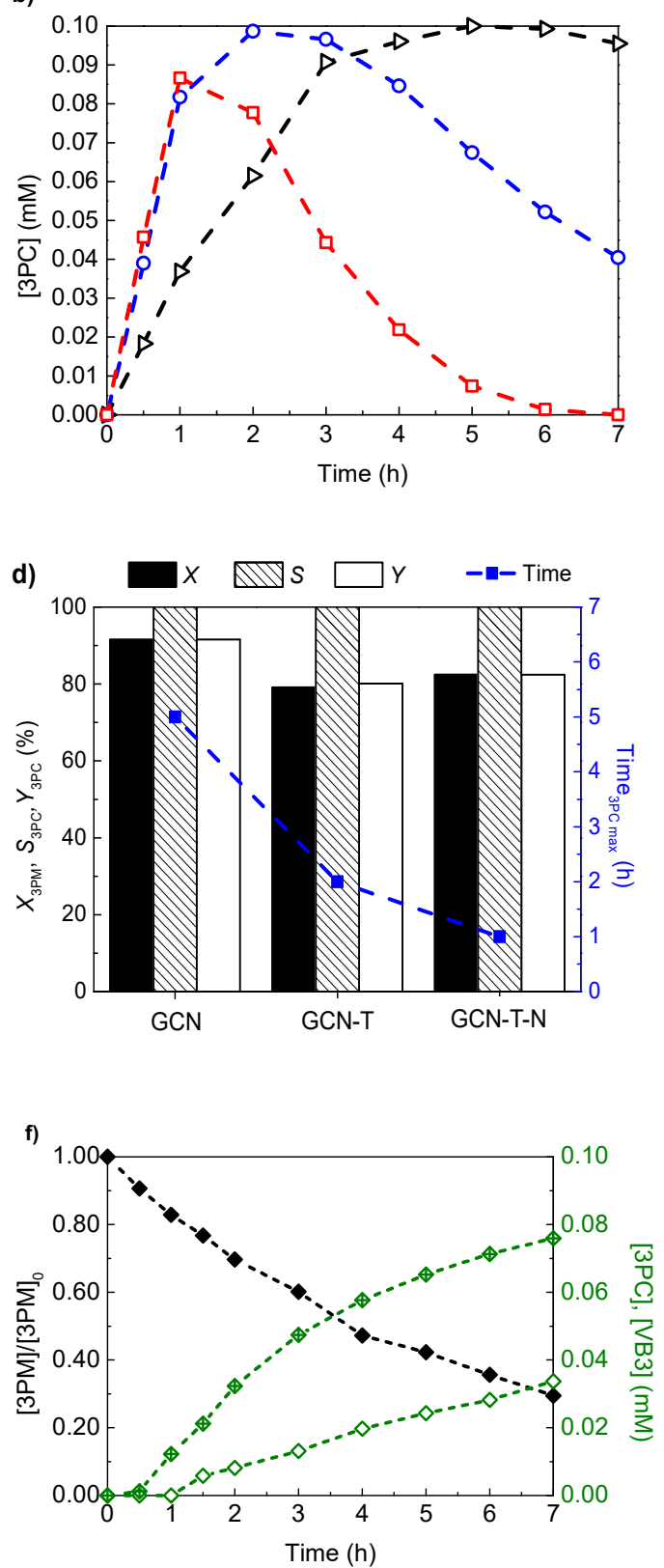

Figure 4. (a) Normalized 3PM, (b) 3PC, and (c) VB3 concentrations over $7 \mathrm{~h}$ of irradiation $\left(\lambda_{\max }=412 \mathrm{~nm}\right)$ using GCN $(\triangleright)$, GCN-T-N $(\square)$, and GCN-T $(\bigcirc)$ as catalysts. (d,e) $X, S$, and $Y$ obtained for the photooxidation of 3PM into 3PC and VB3 at the maximum of their production, respectively. (f) Normalized 3PM $(\diamond), 3 P C(\oplus)$, and VB3 $(\diamond)$ concentrations over $7 \mathrm{~h}$ reaction using immobilized GCN-T-N.

In the absence of a strong oxidizing agent, such as dichromate and permanganate oxides, the partial oxidation of primary alcohols usually occurs in two stages: the initial oxidation to the aldehyde, followed by further oxidation to the acid [29]. Figure $4 b, c$ show the 3PC and VB3 concentration profiles obtained during the photocatalytic conversion of the alcohol (3PM). According to previous scavenging studies using similar GCN-based materials, we determined that the main reactive species that participate in the photocatalytic conversion of $p$-anisyl alcohol into $\mathrm{p}$-anisaldehyde under oxygenated conditions were superoxide radicals and photogenerated holes [12]. Based on our previous findings, a simplified mechanism for the sequential conversion of 3PM into 3PC and finally to VB3 is presented as Scheme 1. Briefly, photoexcited electrons occurring at the conduction band 
react with the adsorbed molecular oxygen $\mathrm{O}_{2}$ to generate the $\mathrm{O}_{2}^{\bullet-}$, which in the presence of the primary alcohol (3PM) produces a charge-separated dehydrogenated radical anion and hydrogen peroxide $\mathrm{H}_{2} \mathrm{O}_{2}$ (Scheme $1 \mathrm{~A}$ ). Oxidative electron transfer to the photogenerated hole of the valence band of the GCN-based catalyst results in the formation of the corresponding aldehyde (3PC). On the other hand, the direct oxidation of the adsorbed alcohol by the photogenerated holes at the valence band of the semiconductor leads to either the formation of an alcohol radical cation or the deprotonated alcohol radical. Either oxidized species adsorbed over the photoexcited GCN material will accept an electron back to produce the aldehyde (3PC). In the present work, the aldehyde is further oxidized into the respective carboxylic acid (VB3, Scheme 1B).

(A)

$$
\mathrm{e}_{\mathrm{CB}}^{-}+\mathrm{O}_{2} \longrightarrow \mathrm{O}_{2}^{--}
$$
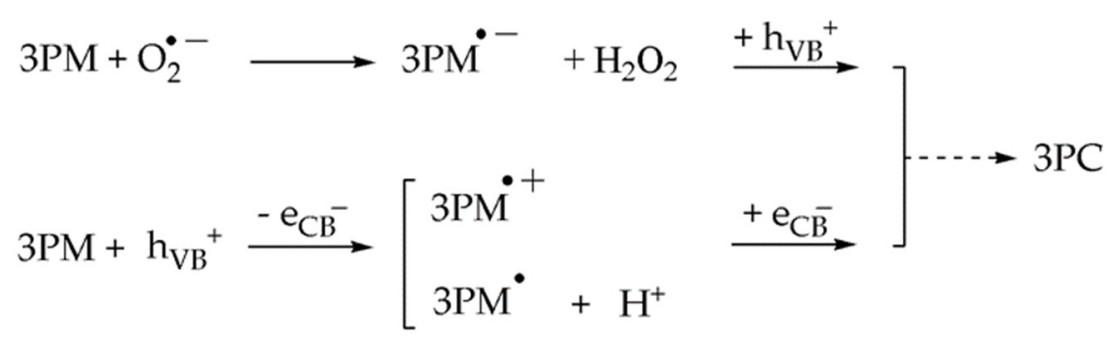

(B)

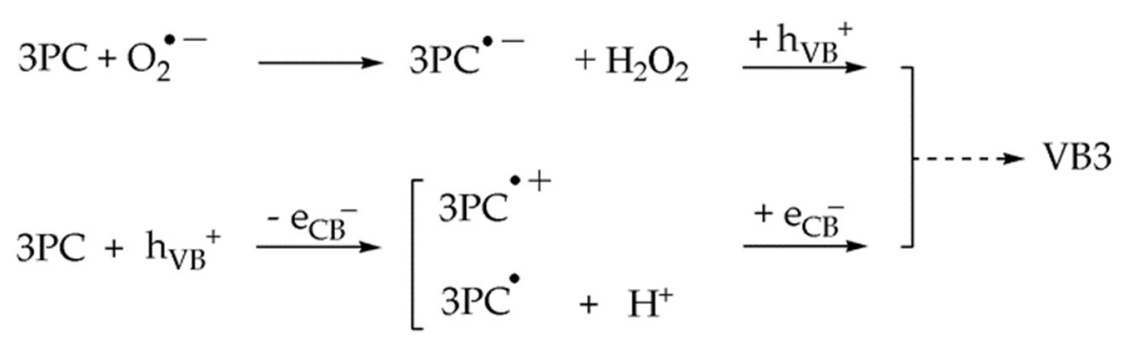

Scheme 1. Simplified mechanism of conversion of 3PM into 3PC (A) and VB3 (B).

From high-performance liquid chromatography (HPLC) analysis (Supplementary Material, Figure S3) and under the experimental conditions, no other intermediates during the photocatalytic synthesis of VB3 through the oxidation of 3PM and 3PC was detected, suggesting that the GCN-T-N photocatalyst is significantly selective for this type of reaction. In terms of maximum production using GCN-T-N as a photocatalyst, $0.09 \mathrm{mM}$ of 3PC was achieved after $1 \mathrm{~h}$ of reaction (Figure $4 \mathrm{~b}$ ) and $0.10 \mathrm{mM}$ of VB3 was achieved after $6 \mathrm{~h}$ (Figure 4c), representing a significant improvement when compared to bulk GCN (c.a. $0.01 \mathrm{mM}$ of VB3 produced after $7 \mathrm{~h}$ of irradiation).

By determining the photocatalytic parameters of conversion $(X)$, selectivity $(S)$ and yield $(Y)$ in the production of both 3PC and VB3, it was possible to compare the performance of the three materials used in the photocatalytic studies. All catalysts showed a high selectivity $(S>99 \%$ ) for aldehyde production (Figure $4 \mathrm{~d}$ ). Bulk GCN revealed a higher conversion and yield (>95\%) than GCN-T and GCN-T-N materials (Figure 4d). However, due to the slower conversion of 3PM when bulk GCN was used as a photocatalyst, the maximum production of $3 \mathrm{PC}$ was obtained after $5 \mathrm{~h}$ of reaction (Figure $4 \mathrm{~d}$ ). Inversely, GCN-T and GCN-T-N revealed a high performance, reaching c.a. $80 \%$ of $X$ and $Y$ in shorter reaction times ( $2 \mathrm{~h}$ and $1 \mathrm{~h}$, respectively; Figure $4 \mathrm{~d}$ ). This relation was also observed in VB3 production (Figure 4e), with GCN-T and GCN-T-N materials being more efficient than bulk GCN. In fact, after $7 \mathrm{~h}$ of reaction, GCN presented a very low $S(16 \%)$ and $Y(16 \%)$ in VB3 production (Figure 4e). In the case of GCN-T, both $S$ and $Y$ increased to $49 \%$ (Figure 4e). GCN-T-N proved to be the best-performing catalyst, achieving $100 \%$ of both $S$ and $Y$ after $7 \mathrm{~h}$ of irradiation (Figure $4 \mathrm{e}$ ). 
As previously mentioned, GCN-T-N presents a highly irregular surface (Figure 1c) and decreased crystallinity (Figure 2), caused by the loss of nitrogen atoms (Table 1) during the post-treatment at high temperatures $\left(620^{\circ} \mathrm{C}\right)$ under nitrogen flow. These alterations suggest increased light absorption in the visible range, creating mid-gap states within the bandgap (Figure 3a, Table 1). Moreover, the reduced recombination between $\mathrm{e}^{-}$and the photogenerated $\mathrm{h}^{+}$(Figure $3 \mathrm{~b}$ ) seems to contribute to an efficient photocatalytic process, favoring the conversion of 3PM into 3PC and VB3 when GCN-T-N was used.

It is known that immobilized catalysts have a decreased interaction with target molecules due to mass transfer limitations promoted by the support [27,30]. Nevertheless, immobilization is a strategy used to avoid post-separation operation units after the process, resulting in considerable advantages both from technological and economic points of view. Therefore, the best-performing catalyst (GCN-T-N) was immobilized in a sodium alginate substrate and its performance was evaluated under the same operational conditions adopted for the powdered materials. Results showed that immobilized GCN-T-N achieved a $71 \% 3 \mathrm{PM}$ conversion, with $41 \%$ of $S$ and $29 \%$ of $Y$ towards VB3 production after $7 \mathrm{~h}$ of irradiation.

The existing reports on the synthesis of VB3 by the photocatalytic conversion of 3PM are compiled in Table 2 and compared to the performance of the system used in the present study.

Table 2. A review of the heterogeneous photocatalytic synthesis of vitamin B3 (VB3) through the conversion of 3-pyridinemethanol (3PM).

\begin{tabular}{|c|c|c|c|c|c|c|c|c|}
\hline Entry & Catalyst & Solvent & Atmosphere & $\begin{array}{l}\text { Irradiation } \\
\text { System }\end{array}$ & $\begin{array}{l}\text { Reaction } \\
\text { Time (h) }\end{array}$ & $X(\%)$ & $S(\%)$ & Ref. \\
\hline 1 & $\mathrm{TiO}_{2}$ & Water & Nitrogen & $\begin{array}{l}\text { High-pressure } \\
\text { UV lamp }\end{array}$ & 0.75 & 30 & 87 & [3] \\
\hline 2 & $\mathrm{TiO}_{2}$ nanotubes & Water & Air & $\begin{array}{c}\text { Fluorescent } \\
\text { lamp }\end{array}$ & n.i. & 15 & 35 & {$[4]$} \\
\hline 3 & $\mathrm{Pt} / \mathrm{TiO}_{2}$ & Water & Air & $\begin{array}{l}\text { Fluorescent } \\
\text { lamp }\end{array}$ & 3 & 15 & 45 & [5] \\
\hline 4 & $\mathrm{TiO}_{2}$ /graphene & Water & Nitrogen & Mercury lamp & 5 & 63 & 35 & [6] \\
\hline 5 & $\mathrm{Ag} @ \mathrm{TiO}_{2} / \mathrm{g}-\mathrm{C}_{3} \mathrm{~N}_{4}$ & Water & Air & Halogen lamp & 9 & 100 & 100 & [7] \\
\hline 6 & GCN & & & & & 98 & 16 & \\
\hline 7 & GCN-T & & & & & 100 & 49 & Present \\
\hline 8 & GCN-T-N & Water & Air & Vis-LED & 7 & 100 & 100 & study \\
\hline 9 & GCN-T-N * & & & & & 71 & 34 & \\
\hline
\end{tabular}

n.i.-not indicated; X: conversion; S: selectivity; * immobilized GCN-T-N.

Most of the studies published deal with the utilization of $\mathrm{TiO}_{2}$-based materials as photocatalysts (Table 2, entries 1-5). Sobahi et al. [7] reported the use of $g-C_{3} N_{4}$ nanosheets decorated with $\mathrm{Ag} @ \mathrm{TiO}_{2}$ nanospheres for the total conversion of 3PM with a $100 \%$ selectivity towards VB3 attained after $9 \mathrm{~h}$ of irradiation under air atmosphere using a conventional halogen light source (Table 2, entry 5). Despite the significant achievements reported in the photocatalytic synthesis of VB3, the results obtained in the present work show superior conversions of 3PM (>98\%; Table 2, entries 6-8) compared with the previous ones (Table 2, entries 1-4). Using the thermal post-treated catalysts (GCN-T and GCN-T-N; Table 2, entries 7 and 8), the selectivity was three and six times higher, respectively, than that of bulk GCN (Table 1, entry 6). The best-performing catalyst, GCN-T-N (Table 2, entry 8), achieved similar results to $\mathrm{Ag} @ \mathrm{TiO}_{2} / \mathrm{g}-\mathrm{C}_{3} \mathrm{~N}_{4}$ (Table 2, entry 5) and in less time (7 h instead of $9 \mathrm{~h}$ ). Moreover, the radiation source adopted in the present study (visible-LEDs) exhibits essential environmental and economic advantages compared to conventional halogen lamps - namely, a relatively long-life span, low cost, and high energy efficiency [31]. The promising results of 3PM conversion and selectivity for VB3 production (71\% and 34\%, respectively) obtained using the immobilized GCN-T-N (Table 2, entry 9) are favorable, foreseeing a more technological approach by avoiding the costly and time-consuming 
catalyst particle separation and the possibility of adapting the immobilized catalyst film to different reactor configurations.

\section{Materials and Methods}

\subsection{Materials}

Dicyandiamide (DCN, 99\%), calcium chloride $\left(\mathrm{CaCl}_{2},>99 \%\right)$, 3-Pyridinemethanol (3PM, 98\%), 3-Pyridinecarboxaldehyde (3PC, 98\%), and Vitamin B3 (VB3, $\geq 98 \%$ ) were purchased from Sigma-Aldrich (Darmstadt, Germany). Formic acid $\left(\mathrm{HCO}_{2} \mathrm{H}, 98 \%\right)$ was acquired from Fluka (Darmstadt, Germany). Methanol $\left(\mathrm{CH}_{3} \mathrm{OH}, 99.6 \%\right)$ and sodium alginate were purchased from VWR ${ }^{\mathrm{TM}}$ (Arnhem, Netherlands). All the reagents were used without further purification. Ultra-pure water $\left(18 \mathrm{M} \Omega \mathrm{cm}^{-1}\right)$ was obtained from a Millipore Milli-Q water purification system (Darmstadt, Germany).

\subsection{Synthesis of Metal-Free GCN-Based Catalysts}

The bulk GCN material was prepared by thermal decomposition of DCN as described elsewhere [18]. Briefly, $2 \mathrm{~g}$ of the precursor DCN was placed in a covered crucible and heated in a muffle to $550{ }^{\circ} \mathrm{C}$ for $4 \mathrm{~h}$ with a heating rate of $2{ }^{\circ} \mathrm{C} \mathrm{min}-1$ under a static air atmosphere. The obtained yellow bulk GCN material was ground, washed with deionized water, and dried at $60^{\circ} \mathrm{C}$ for $12 \mathrm{~h}$ under a static air atmosphere. In a second step, thermal exfoliation was carried out by placing $0.95 \mathrm{~g}$ of bulk GCN in an open crucible, followed by a temperature rise to $500{ }^{\circ} \mathrm{C}$ using a heating rate of $2{ }^{\circ} \mathrm{C} \mathrm{min}-1$ in the muffle under static air atmosphere. The temperature was maintained for $2 \mathrm{~h}$, and the resulting material was denoted as GCN-T. For GCN-T-N material synthesis, the bulk GCN was placed into a quartz tubular reactor, heated until $620^{\circ} \mathrm{C}$ at $5^{\circ} \mathrm{C} \mathrm{min}^{-1}$, and the treatment remained for $2 \mathrm{~h}$ under an inert atmosphere (nitrogen at $80 \mathrm{~mL} \mathrm{~min}^{-1}$ ).

The GCN-T-N powder was dispersed on sodium alginate (SA) polymer to immobilize the photocatalyst by adapting the procedure described elsewhere [32]. Concisely, an aqueous solution containing $25 \mathrm{~g} \mathrm{~L}^{-1}$ of SA was magnetically stirred and heated at $50{ }^{\circ} \mathrm{C}$ for $2 \mathrm{~h}$. Then, $50 \mathrm{mg}$ of GCN-T-N was added under stirring until a homogeneous dispersion in the SA solution was obtained. To favor the gelation process and the cross-linking between SA and the photocatalyst, the addition of $25 \mathrm{~mL}$ of $3 \%(w / v) \mathrm{CaCl}_{2}$ aqueous solution was carried out. The final dispersion was stirred for $8 \mathrm{~h}$ at $50{ }^{\circ} \mathrm{C}$. Then, the dispersion was placed in a glass plate and spread using a knife film applicator (Elcometer 3580, Warren, USA). The obtained flat film ( $40 \mathrm{~mm} \times 50 \mathrm{~mm}$, with $5 \mathrm{~mm}$ of thickness) was washed and stored in deionized water until further use.

\subsection{Photocatalyst Characterization}

The morphology of the materials was assessed by scanning electron microscopy (SEM) in an FEI Quanta 400 FEG ESEM/EDAX Genesis X4M (15 keV) instrument (Hillsboro, USA). The chemical composition of the materials was determined by elemental analysis. Carbon, nitrogen, and hydrogen were determined in a Vario micro cube analyzer (Elementar $\mathrm{GmbH}$, Frankfurt, Germany) by the combustion of the sample at $1050{ }^{\circ} \mathrm{C}$. Each sample was analyzed in triplicate. X-ray diffraction (XRD) analysis was carried out in a PANalytical $X^{\prime}$ Pert MPD instrument (Malvern, United Kingdom) equipped with an $X^{\prime}$ Celerator detector and secondary monochromator $(\mathrm{Cu} \mathrm{Ka} \mathrm{k}=0.154 \mathrm{~nm}, 50 \mathrm{kV}, 40 \mathrm{~mA}$; data recorded at a $0.017^{\circ}$ step size, $100 \mathrm{~s} / \mathrm{step}$ ). X-ray photoelectron spectroscopy analyses (XPS) were carried out in a Kratos AXIS Ultra HAS equipment and Al monochromator operating at $15 \mathrm{kV}$ ( 90 W, Manchester, United Kingdom) in hybrid mode. The obtained spectra were analyzed and deconvoluted using the CasaXPS software. The diffuse-reflectance UV-Vis spectra (DR UV-Vis) of the materials were obtained on a JASCO V-560 UV-Vis spectrophotometer equipped with an integrating sphere attachment (JASCO ISV-469, Pfungstadt, Germany). The bandgap of the photocatalysts was determined from the respective Tauc plot. The Brunauer-Emmett-Teller (BET) specific surface area $\left(S_{\mathrm{BET}}\right)$ was determined through the $\mathrm{N}_{2}$ adsorption data at $-196{ }^{\circ} \mathrm{C}$ in the relative pressure range $0.05-0.20$, using a Quantachrome 
NOVA 4200e apparatus (Boynton Beach, USA). Solid-state photoluminescence (PL) spectra were obtained at room temperature on a JASCO (FP 82000) fluorescence spectrometer (Pfungstadt, Germany) equipped with a 150W Xenon lamp as a light source using an excitation and emission bandwidth fixed at $2.5 \mathrm{~nm}$. The excitation wavelength was set at $370 \mathrm{~nm}$ and the emission was measured in the 380-650 $\mathrm{nm}$ range.

\subsection{Photocatalytic Experiments}

The photocatalytic efficiency of GCN, GCN-T, and GCN-T-N catalyst materials was studied in the selective oxidation of 3-pyridinemethanol (3PM) into Vitamin B3 (VB3) under visible-LED irradiation $\left(\lambda_{\max }=412 \mathrm{~nm}\right)$. All experiments were carried out in a cylindrical borosilicate reactor filled with $0.10 \mathrm{mM}$ aqueous solution of $3 \mathrm{PM}$ at $20{ }^{\circ} \mathrm{C}$ and a catalyst load of $1 \mathrm{~g} \mathrm{~L}^{-1}$. The experiments were performed under continuous magnetic stirring and oxygen saturation (continuous airflow), using a four visible LED system $\left(\lambda_{\max }=412 \mathrm{~nm}\right)$ as the radiation source. The average irradiance of each LED was $49.8 \mathrm{~mW} \mathrm{~cm}^{-2}$, as determined by using a UV-vis spectroradiometer (OceanOptics USB2000 +, Ocean Insight, Duiven, The Netherlands). A dark period of $30 \mathrm{~min}$ was initially established to reach the adsorptiondesorption equilibrium. The suspension was irradiated for $7 \mathrm{~h}$ and the 3PM, 3PC, and VB3 concentrations were monitored by High-Performance Liquid Chromatography (HPLC) using a Shimadzu Corporation apparatus equipped with a Diode Array Detector (SPD M20A, Kyoto, Japan). A Surf C18 AQ 100A $3 \mu \mathrm{m}(100 \times 2.1 \mathrm{~mm})$ column was used with a solvent delivery pump (LC-30AD) at a flow rate fixed at $0.25 \mathrm{~mL} \mathrm{~min}{ }^{-1}$. The temperatures of the column oven and autosampler were set at $40{ }^{\circ} \mathrm{C}$ and $4.0^{\circ} \mathrm{C}$, respectively. An equilibrated mixture of acetonitrile (A) and $40 \mathrm{mM}$ ammonium acetate (B) with a ratio of 2:98 (A:B) was isocratically eluted for $15 \mathrm{~min}$. The 3PM, 3PC, and VB3 concentrations were determined at $260 \mathrm{~nm}, 230 \mathrm{~nm}$, and $215 \mathrm{~nm}$, respectively.

According to the chemical stoichiometry of the oxidative reaction, one molecule of 3PM can be oxidized to one molecule of 3PC, which is consequently oxidized to VB3 (1:1:1). The synthesis of 3PC and VB3 only starts when the radiation source is turned on, which means that the initial concentration of both molecules $\left(Z_{0}\right)$ is zero. The performance of the reaction was evaluated in terms of 3PM conversion $(X)$, selectivity $(S)$, and yield $(Y)$ towards the 3PC and VB3 production (see Supporting Data).

Regarding the immobilized GCN-T-N, the polymeric material was placed in the photoreactor with a cylindrical shape around its inside walls (Supplementary Material, Figure S4. The photocatalytic reaction was carried out under the same reaction conditions as the powdered catalysts.

\section{Conclusions}

GCN-based photocatalysts obtained through its thermal post-treatment under air (GCN-T) and nitrogen (GCN-T-N) atmospheres were successfully applied in the synthesis of vitamin B3 (VB3) through the oxidation of 3-pyridinemethanol (3PM) under visible-LED radiation $\left(\lambda_{\max }=412 \mathrm{~nm}\right)$. The different conditions applied in the post-treatment to bulk GCN led to less crystalline materials with distinct morphological, optical, and electronic properties.

The oxidation of the starting alcohol (3PM) resulted in the formation of the respective aldehyde (3-pyridinecarboxaldehyde; 3PC) and the nicotinic acid (VB3).

The thermal post-treatment proved to positively impact the photocatalytic performance of the modified catalysts (GCN-T and GCN-T-N) compared to bulk GCN. GCN-T-N was revealed to be highly efficient, achieving a 100\% 3PM conversion and selectivity towards VB3 production after $7 \mathrm{~h}$ of irradiation, corresponding to the best result among all the catalysts already reported in the literature.

The highly defective surface of GCN-T-N, with reduced crystallinity and improved photo absorption, contributes to enhancing the photocatalytic activity compared to the other tested materials. The irregular structure caused by the presence of nitrogen vacancies 
in the heptazine rings led to the creation of mid-gap states within the bandgap of the catalyst, which improved its oxidative ability.

The study involving the use of immobilized GCN-T-N revealed a promising potential of this photocatalytic system to be used in real-case applications.

Supplementary Materials: The following are available online: Debye-Scherrer equation definition; photocatalytic parameters calculation and Figures S1-S4, and Table S1.

Author Contributions: Conceptualization, R.A.F., M.J.S., J.L.F. and C.G.S.; methodology, R.A.F., M.J.S., J.L.F. and C.G.S.; investigation, R.A.F. and M.J.S.; resources, M.J.S., J.L.F. and C.G.S.; writingoriginal draft preparation, R.A.F. and M.J.S.; writing-review and editing, M.J.S., J.L.F. and C.G.S.; supervision, M.J.S., J.L.F. and C.G.S.; funding acquisition, M.J.S., J.L.F. and C.G.S. All authors have read and agreed to the published version of the manuscript.

Funding: This work was financially supported by LA/P/0045/2020 (ALiCE) and Base-UIDB/50020/2020UIDP/50020/2020 (LSRE-LCM) financed by national funds through FCT/MCTES (PIDDAC), and by the Projects POCI-01-0145-FEDER-030674 and POCI-01-0145-FEDER-031398 funded by ERDF through COMPETE2020, Programa Operacional Competitividade e Internacionalização (POCI) and by national funds through FCT (Fundação para a Ciência e a Tecnologia). R.A.F. acknowledges the PhD fellowship funded by Project NORTE-08-5369-FSE-000028, supported by Norte Portugal Regional Operational Programme (NORTE 2020), under the PORTUGAL 2020 Partnership Agreement, through the European Social Fund (ESF).

Institutional Review Board Statement: Not applicable.

Informed Consent Statement: Not applicable.

Data Availability Statement: Not applicable.

Acknowledgments: We are indebted to Carlos Sá (CEMUP, Porto) and Pedro Tavares (UTAD) for technical assistance and advice with the SEM and XRD analyses, respectively.

Conflicts of Interest: The authors declare no conflict of interest.

Sample Availability: Not available.

\section{References}

1. Chuck, R. Technology development in nicotinate production. Appl. Catal. A Gen. 2005, 280, 75-82. [CrossRef]

2. Badawy, A.A.-B. Pellagra and alcoholism: A biochemical perspective. Alcohol Alcohol. 2014, 49, 238-250. [CrossRef]

3. Spasiano, D.; Marotta, R.; Di Somma, I.; Mancini, G. Production of pyridinecarboxy aldehydes, nicotinic and isonicotinic and picolinic acids by $\mathrm{TiO}_{2}$-sacrificial photocatalysis at ambient conditions and in aqueous solution through artificial solar radiation. Appl. Catal. B Environ. 2015, 163, 248-257. [CrossRef]

4. Yurdakal, S.; Çetinkaya, S.; Şarlak, M.B.; Özcan, L.; Loddo, V.; Palmisano, L. Photoelectrocatalytic oxidation of 3-pyridinemethanol to 3-pyridinemethanal and vitamin $\mathrm{B} 3$ by $\mathrm{TiO}_{2}$ nanotubes. Catal. Sci. Technol. 2020, 10, 124-137. [CrossRef]

5. Yurdakal, S.; Yanar, Ş.Ö.; Çetinkaya, S.; Alagöz, O.; Yalçın, P.; Özcan, L. Green photocatalytic synthesis of vitamin B3 by Pt loaded $\mathrm{TiO}_{2}$ photocatalysts. Appl. Catal. B Environ. 2017, 202, 500-508. [CrossRef]

6. Alfè, M.; Spasiano, D.; Gargiulo, V.; Vitiello, G.; Di Capua, R.; Marotta, R. $\mathrm{TiO}_{2}$ /graphene-like photocatalysts for selective oxidation of 3-pyridine-methanol to vitamin B3 under UV/solar simulated radiation in aqueous solution at room conditions: The effect of morphology on catalyst performances. Appl. Catal. A Gen. 2014, 487, 91-99. [CrossRef]

7. Sobahi, T.R.; Amin, M.S. Upgrading the photocatalytic achievement of $\mathrm{g}^{-} \mathrm{C}_{3} \mathrm{~N}_{4}$ nanosheets along decoration with $\mathrm{Ag} @ \mathrm{TiO}{ }_{2}$ nanospheres for the preparation of vitamin B3. Appl. Nanosci. 2019, 9, 1621-1636. [CrossRef]

8. Friedmann, D.; Hakki, A.; Kim, H.; Choi, W.; Bahnemann, D. Heterogeneous photocatalytic organic synthesis: State-of-the-art and future perspectives. Green Chem. 2016, 18, 5391-5411. [CrossRef]

9. Miller, T.S.; Jorge, A.B.; Suter, T.M.; Sella, A.; Corà, F.; McMillan, P.F. Carbon nitrides: Synthesis and characterization of a new class of functional materials. Phys. Chem. Chem. Phys. 2017, 19, 15613-15638. [CrossRef]

10. Yuan, Y.; Zhang, L.; Xing, J.; Utama, M.I.B.; Lu, X.; Du, K.; Li, Y.; Hu, X.; Wang, S.; Genç, A.; et al. High-yield synthesis and optical properties of $\mathrm{g}-\mathrm{C}_{3} \mathrm{~N}_{4}$. Nanoscale 2015, 7, 12343-12350. [CrossRef]

11. Da Silva, E.S.; Moura, N.M.M.; Coutinho, A.; Dražić, G.; Teixeira, B.M.S.; Sobolev, N.A.; Silva, C.G.; Neves, M.G.P.M.S.; Prieto, M.; Faria, J.L. $\beta$-Cyclodextrin as a precursor to holey C-doped $\mathrm{g}-\mathrm{C}_{3} \mathrm{~N}_{4}$ nanosheets for photocatalytic hydrogen generation. ChemSusChem 2018, 11, 2681-2694. [CrossRef]

12. Fernandes, R.A.; Sampaio, M.J.; Faria, J.L.; Silva, C.G. Aqueous solution photocatalytic synthesis of $p$-anisaldehyde by using graphite-like carbon nitride photocatalysts obtained via the hard-templating route. RSC Adv. 2020, 10, 19431-19442. [CrossRef] 
13. Li, Y.; Wang, M.-Q.; Bao, S.-J.; Lu, S.; Xu, M.; Long, D.; Pu, S. Tuning and thermal exfoliation graphene-like carbon nitride nanosheets for superior photocatalytic activity. Ceram. Int. 2016, 42, 18521-18528. [CrossRef]

14. Niu, P.; Zhang, L.; Liu, G.; Cheng, H.-M. Graphene-like carbon nitride nanosheets for improved photocatalytic activities. Adv. Funct. Mater. 2012, 22, 4763-4770. [CrossRef]

15. Song, X.; Zhang, X.; Li, X.; Che, H.; Huo, P.; Ma, C.; Yan, Y.; Yang, G. Enhanced light utilization efficiency and fast charge transfer for excellent $\mathrm{CO}_{2}$ photoreduction activity by constructing defect structures in carbon nitride. J. Colloid Interface Sci. 2020, 578, 574-583. [CrossRef]

16. Lopes, J.C.; Sampaio, M.J.; Fernandes, R.A.; Lima, M.J.; Faria, J.L.; Silva, C.G. Outstanding response of carbon nitride photocatalysts for selective synthesis of aldehydes under UV-LED irradiation. Catal. Today 2020, 357, 32-38. [CrossRef]

17. Svoboda, L.; Praus, P.; Lima, M.J.; Sampaio, M.J.; Matýsek, D.; Ritz, M.; Dvorský, R.; Faria, J.L.; Silva, C.G. Graphitic carbon nitride nanosheets as highly efficient photocatalysts for phenol degradation under high-power visible LED irradiation. Mater. Res. Bull 2018, 100, 322-332. [CrossRef]

18. Lima, M.J.; Silva, A.M.T.; Silva, C.G.; Faria, J.L. Graphitic carbon nitride modified by thermal, chemical and mechanical processes as metal-free photocatalyst for the selective synthesis of benzaldehyde from benzyl alcohol. J. Catal. 2017, 353, 44-53. [CrossRef]

19. Lei, G.; Cao, Y.; Zhao, W.; Dai, Z.; Shen, L.; Xiao, Y.; Jiang, L. Exfoliation of graphitic carbon nitride for enhanced oxidative desulfurization: A facile and general strategy. ACS Sustain. Chem. Eng. 2019, 7, 4941-4950. [CrossRef]

20. Dong, G.; Wen, Y.; Fan, H.; Wang, C.; Cheng, Z.; Zhang, M.; Ma, J.; Zhang, S. Graphitic carbon nitride with thermally-induced nitrogen defects: An efficient process to enhance photocatalytic $\mathrm{H}_{2}$ production performance. RSC Adv. 2020, 10, 18632-18638. [CrossRef]

21. Sun, B.; Yu, H.; Yang, Y.; Li, H.; Zhai, C.; Qian, D.-J.; Chen, M. New complete assignment of X-ray powder diffraction patterns in graphitic carbon nitride using discrete Fourier transform and direct experimental evidence. Phys. Chem. Chem. Phys. 2017, 19, 26072-26084. [CrossRef]

22. Fina, F.; Callear, S.K.; Carins, G.M.; Irvine, J.T.S. Structural investigation of graphitic carbon nitride via XRD and neutron diffraction. Chem. Mater. 2015, 27, 2612-2618. [CrossRef]

23. Kang, Y.; Yang, Y.; Yin, L.-C.; Kang, X.; Liu, G.; Cheng, H.-M. An amorphous carbon nitride photocatalyst with greatly extended visible-light-responsive range for photocatalytic hydrogen generation. Adv. Mater. 2015, 27, 4572-4577. [CrossRef]

24. Langford, J.I.; Wilson, A.J.C. Scherrer after sixty years: A survey and some new results in the determination of crystallite size. J. Appl. Crystallogr. 1978, 11, 102-113. [CrossRef]

25. Tang, J.-Y.; Kong, X.Y.; Ng, B.-J.; Chew, Y.-H.; Mohamed, A.R.; Chai, S.-P. Midgap-state-mediated two-step photoexcitation in nitrogen defect-modified g- $\mathrm{C}_{3} \mathrm{~N}_{4}$ atomic layers for superior photocatalytic $\mathrm{CO}_{2}$ reduction. Catal. Sci. Technol. 2019, 9, 2335-2343. [CrossRef]

26. Chen, Y.; Wang, B.; Lin, S.; Zhang, Y.; Wang, X. Activation of $\mathrm{n} \rightarrow \pi^{*}$ transitions in two-dimensional conjugated polymers for visible light photocatalysis. J. Phys. Chem. C 2014, 118, 29981-29989. [CrossRef]

27. Fernandes, R.A.; Sampaio, M.J.; Dražić, G.; Faria, J.L.; Silva, C.G. Efficient removal of parabens from real water matrices by a metal-free carbon nitride photocatalyst. Sci. Total Environ. 2019, 716, 135346. [CrossRef]

28. Wu, P.; Wang, J.; Zhao, J.; Guo, L.; Osterloh, F.E. Structure defects in g- $\mathrm{C}_{3} \mathrm{~N}_{4}$ limit visible light driven hydrogen evolution and photovoltage. J. Mater. Chem. A 2014, 2, 20338-20344. [CrossRef]

29. Smith, M.B.; March, J. March's Advanced Organic Chemistry, 6th ed.; John Wiley \& Sons, Inc.: Hoboken, NJ, USA, 2007; ISBN 9780471720911.

30. Dijkstra, M.F.J.; Michorius, A.; Buwalda, H.; Panneman, H.J.; Winkelman, J.G.M.; Beenackers, A.A.C. Comparison of the efficiency of immobilized and suspended systems in photocatalytic degradation. Catal. Today 2001, 66, 487-494. [CrossRef]

31. Jo, W.-K.; Tayade, R.J. New generation energy-efficient light source for photocatalysis: LEDs for environmental applications. Ind. Eng. Chem. Res. 2014, 53, 2073-2084. [CrossRef]

32. He, P.; Tang, X.; Chen, L.; Xie, P.; He, L.; Zhou, H.; Zhang, D.; Fan, T. Patterned Carbon Nitride-Based Hybrid Aerogel Membranes via 3D Printing for Broadband Solar Wastewater Remediation. Adv. Funct. Mater. 2018, 28, 1801121. [CrossRef] 